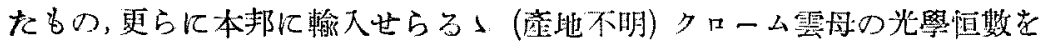
も，沜せて测定した。

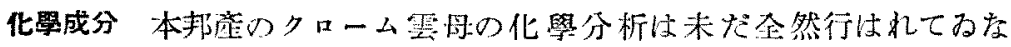
い。この事はその産出の稀であること，少量であるとといに基くものであ る。然し $\mathrm{Cr}$ の存在结何れ女定性的には確翟されてるる。

\title{
朝鮮笏洞金山産キユーバ喭及ヴアレリー磄 の反射影微鏡的研究
}

理學士渡邊武 罗

\section{緒 言}

第洞產礦石老研究中, 新に $\mathrm{Cu}-\mathrm{Fe}-\mathrm{S}$ 系の礦物中比较的产出稀なるキュ

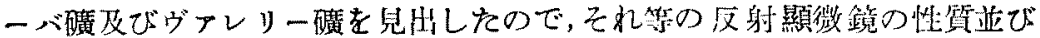

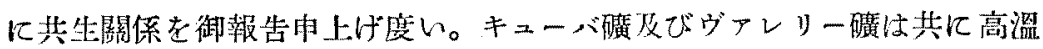

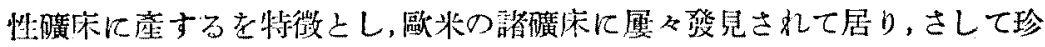

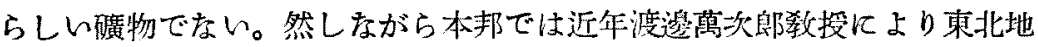

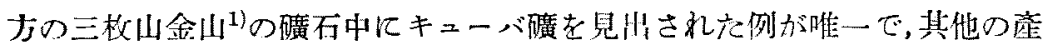

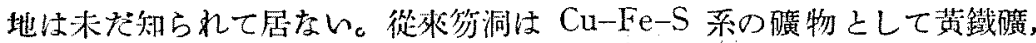

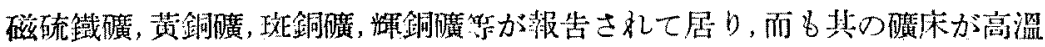

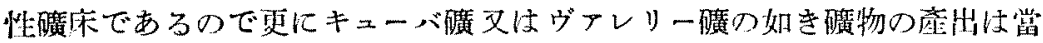
然豫期されて居たのであるが，最近迄闪腿的には勿諭顯微鏡的にも見出せ

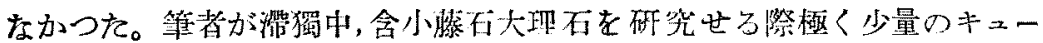

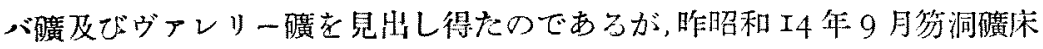

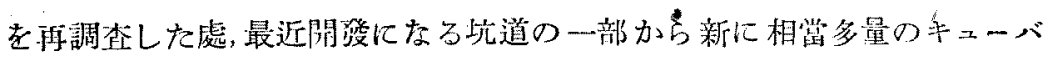

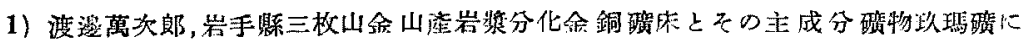

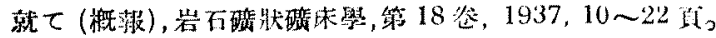




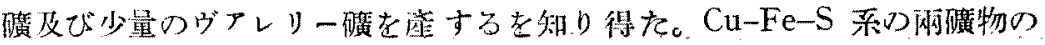

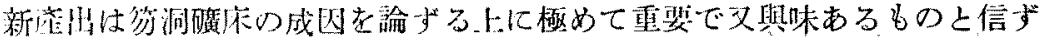

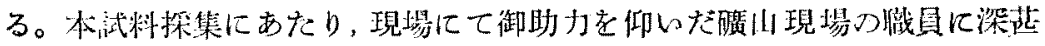

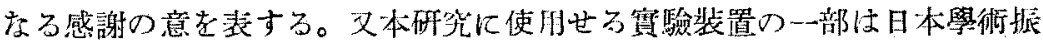

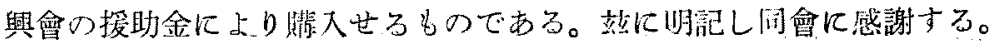

\section{磎石試料の産狀}

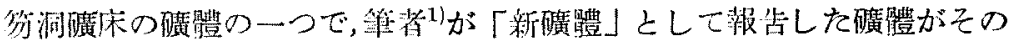

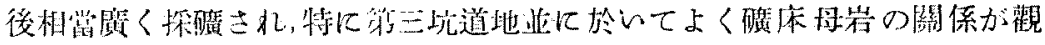

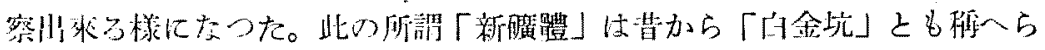

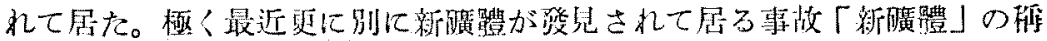

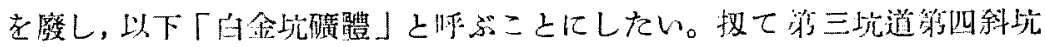

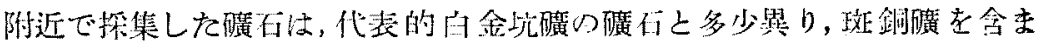

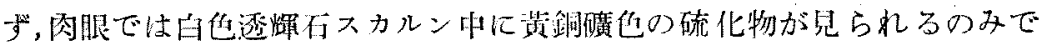

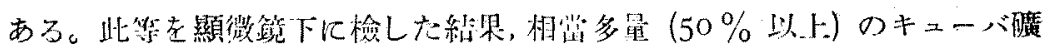

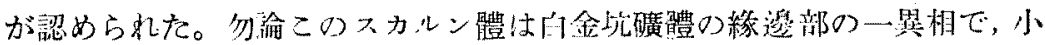

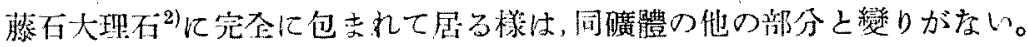

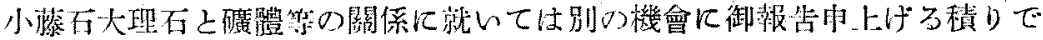
ある。

\section{キューバ磄 (Cubanite, CuFeS ${ }_{2}$ )}

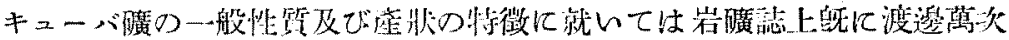

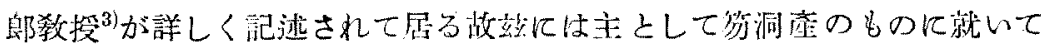

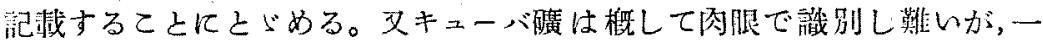

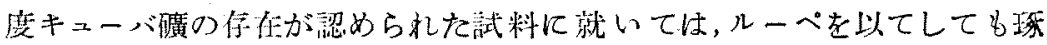

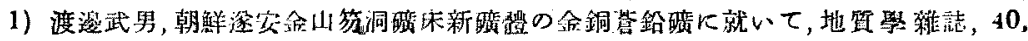
$1933,70 \sim 85,125 \sim 148,188 \sim 209$ 自。

2) Watanabe $T$., Kotoit, ein neues gesteinsbildendes Magnesiumborat, Min. Petro. Mitt, 50, 1939, 441 463:

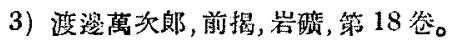




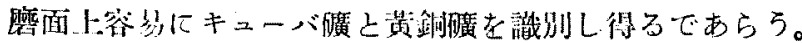

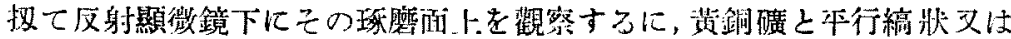

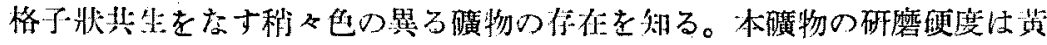

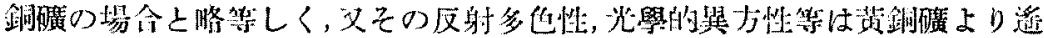

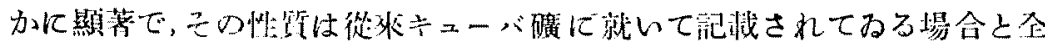
く一致する。

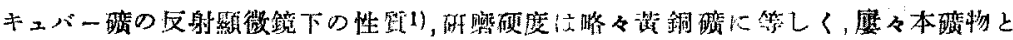

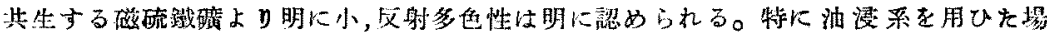

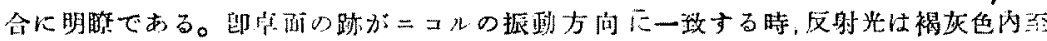

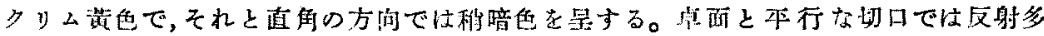

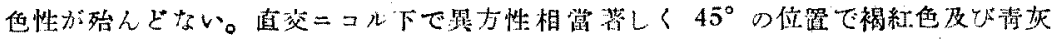

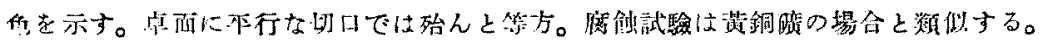
КOH に上る作用が多少暴る場合肪ある。

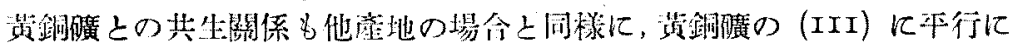

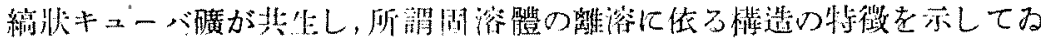
了(行壹阅)。

\section{ヴフレリー礦（Valleriite, $\mathrm{Cu}_{42} \mathrm{Fe}_{4} \mathrm{~S}_{7}$ 叉は $\mathrm{Cu}_{3} \mathrm{Fe}_{4} \mathrm{~S}_{7}$ )}

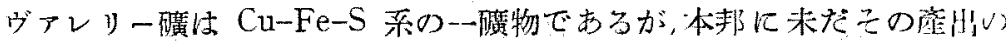

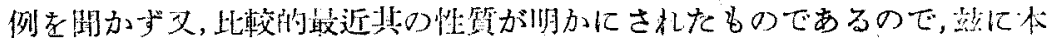
磺物の現任迄の知識の紨介老率み上5。

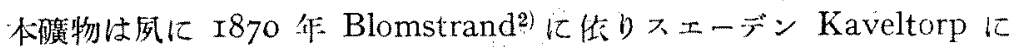

1) Ramdohr, P. : Beobachtungen am Chalmersit. Metall u. Erz. XXII, 1925, $471 \sim 474$.

Ramdohr, P. : Neue Mikzoskopische Beobachtungen am Cubanit(Chalmersit) und Überlegungen über seine Lagerstättenkundlichen Stellung. Zeit. prakt. Geol. $36,1928.1 \sim 10$

Schneiderhöhn. Ramdohr: Lehrbuch der Erzmikroskopie, Bd. II, 1931 $360 \sim 366$.

2) Blomstrand, C. W. : Om nagra nya svenska mineralier samt om magnetkisens sammansättning. Ofersigt Kongl. Vetenskaps Alaad. Förh. 1870 (Ramdohr,

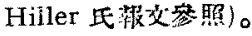




\section{第壹圖}

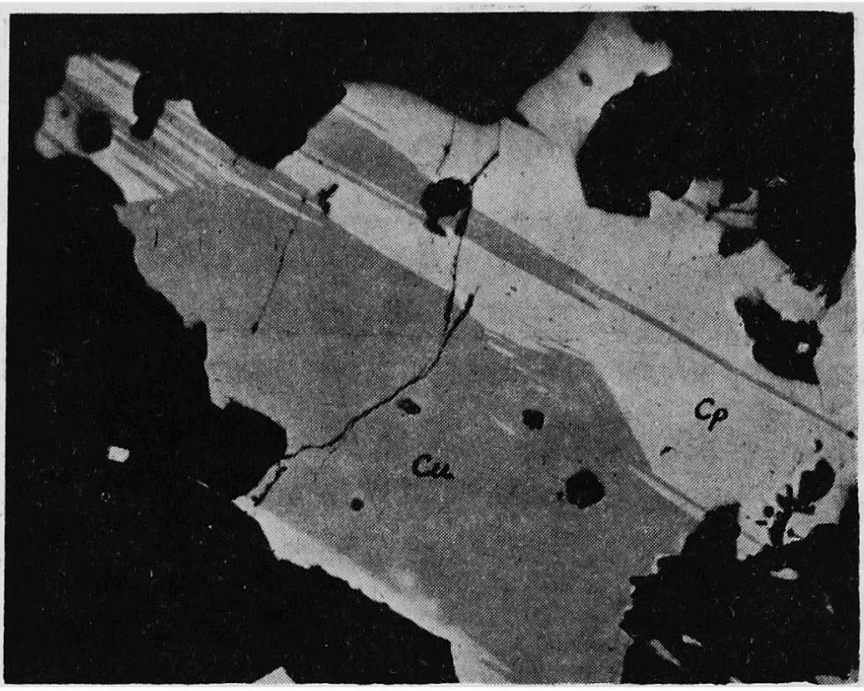

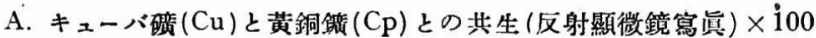

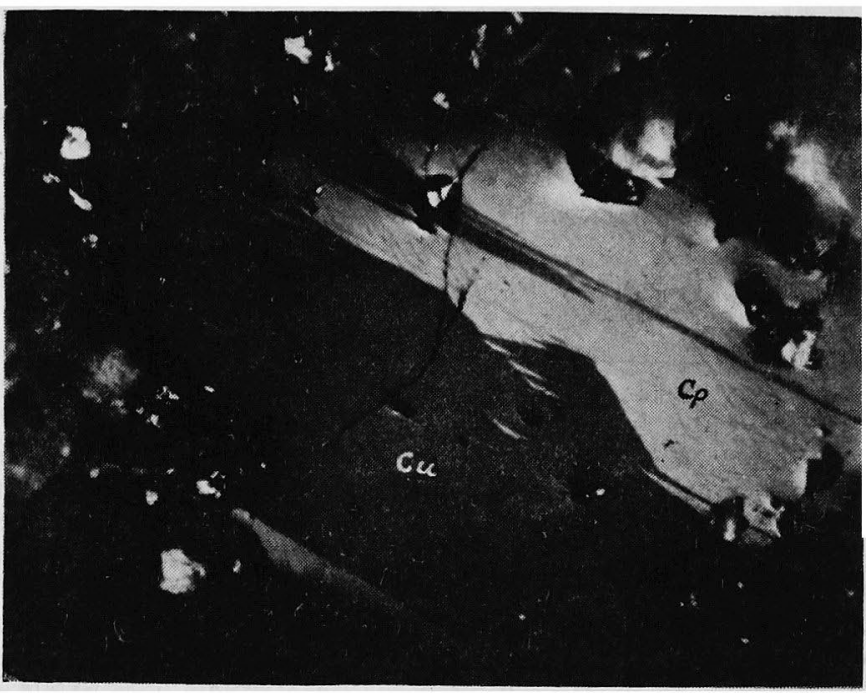

B. 同上、ニコルを略ト十字にした場合 


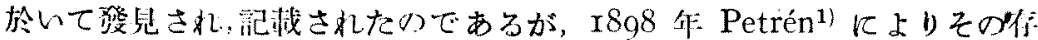

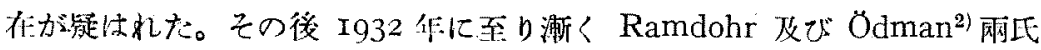

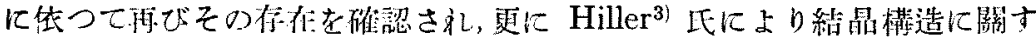
る研究が行はれたのである。一方本硣物は反射顯䍀鏡下で非常に顯著な性:

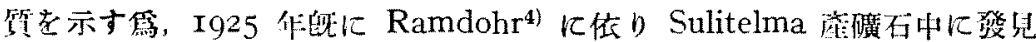

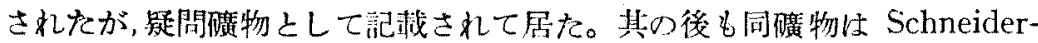

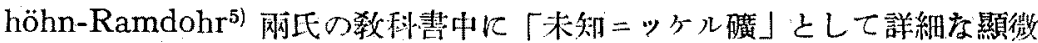

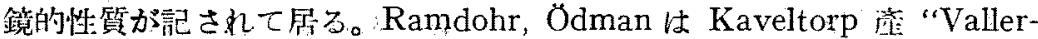
iite”を研究した結果前記「未知ニッケル礦」と全く性筫が一致する事を

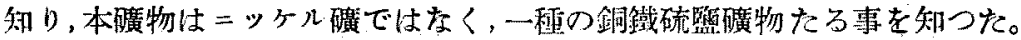
その化學成分注純粹仼料の分離が非常に困難であつたいめ，賞時 $\mathrm{Cu}_{3} \mathrm{Fe}_{5} \mathrm{~S}_{9}$ 又は $\mathrm{Cu}_{3} \mathrm{Fe}_{4} \mathrm{~S}_{7}$ 上推定されたのである。更に最近 Hiller は $\mathrm{X}$ 線的研觉を 行方、際し新分析武料の完全分離に努力したが成功せず，同氏は $\mathrm{Cu}_{2} \mathrm{Fe}_{4} \mathrm{~S}_{7}$ 头は $\mathrm{Cu}_{3} \mathrm{Fe}_{4} \mathrm{~S}_{7}$ なる成分を有するものと若へて居り，現在迄一義的に決定 されて居ないのである。

Hillerの結果によると，ヴメレリー磺は斜方昆系に屬し，格子恒數は $\mathrm{a}=$

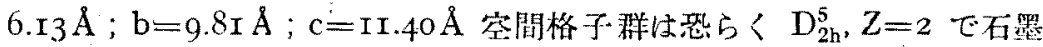

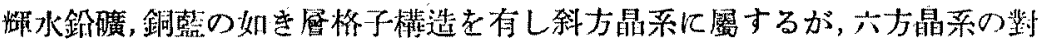
稉に近いもの有すると云ふ。

\section{第洞産ヴレリー碾の座狀}

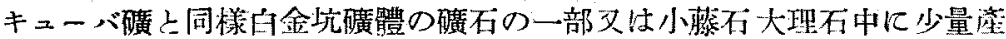

1) Petrén, J.: Om den s. k. Valleriiten. Geol. Fören. i Stockholm Förh. 20. (1898).

2) Ramdohr, P. u. Ödman, O. : Valleriit, Geol, Fören. Stockholm Förh, 54, 1932, 89 98.

3) Hiller, J. E. : Zur Fíristallstruktur des Valleriits: Z. X. Bd, 101 1939, 425 434.

4) Ramdohr, P.: 前揭（1925).

5) Schneiderhöhn, H. u. Ramdohr. P. : Lehrbuch der Erzmikroskopie Bd. II. "Unbekanntes Nickelerz" 127 130. 


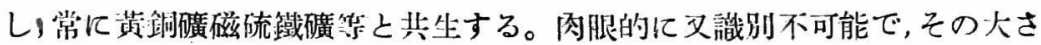
も O.I mm 程度以下のものが多い。反射顯微鏡下に觀祭するに, キューバ

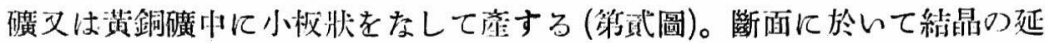

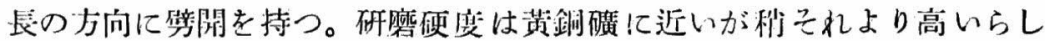

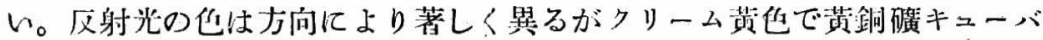

第或圖

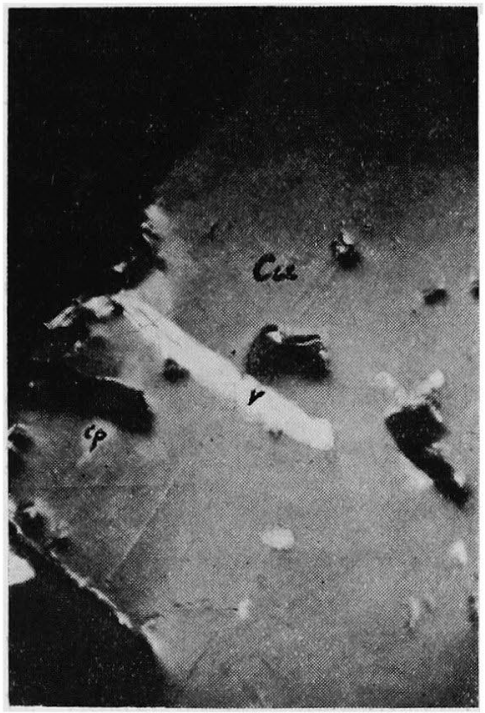

A. 反射光線十字にする $\times 400$ $450^{\circ}$ の位预

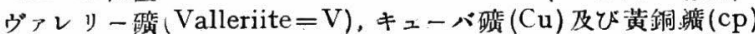

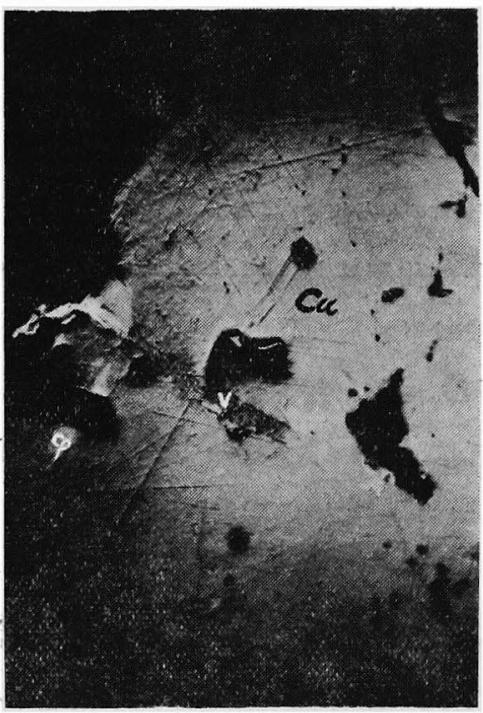

B. 1 ニコル 油浸 $\times 400$ (A と同一場所)

礓に類似してるる。結晶の延辰の方向に平行な場命キューバ礦の場合より

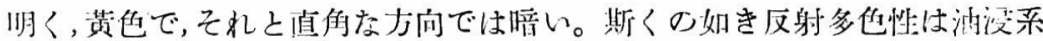
左用ひれば特に顯藷となる。

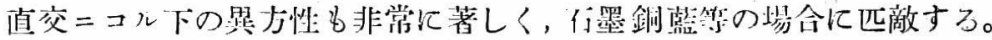
綃晶の延長の方向及びそれて直仢の方向に於て消光し， $45^{\circ}$ の位置にて最 大朋さを示す(籍式圆 A)。即ち一回缚中四度消光す。これも油浸系では更 に著しくなる。 


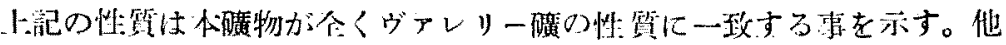

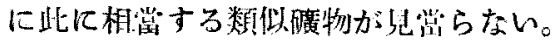

\section{共生磄物之成因的考察}

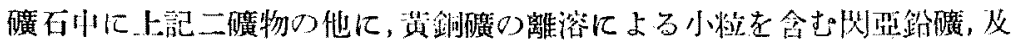

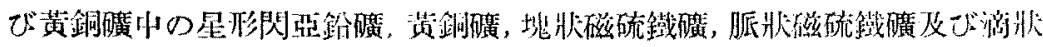

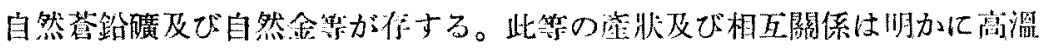

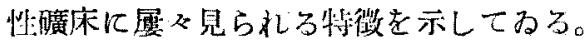

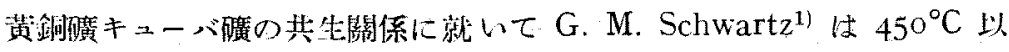

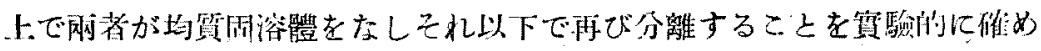

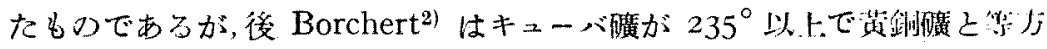

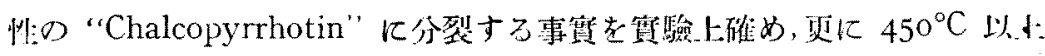

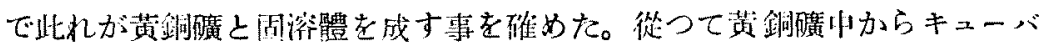

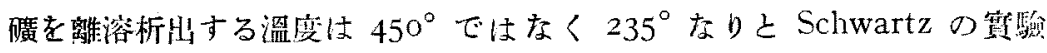

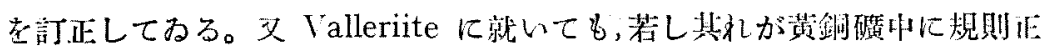

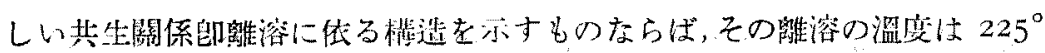
であららと推論してるる。

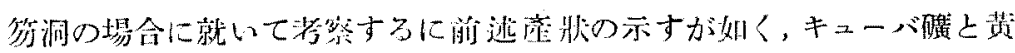

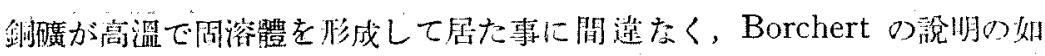
く恐らく $235^{\circ}$ 以上の温度で生成されたものであらう。又䈃洞ではヴァレ

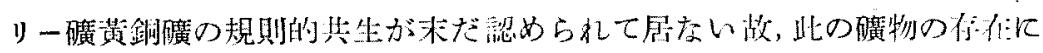

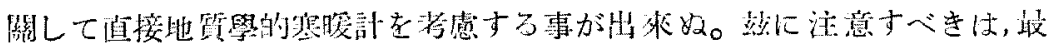

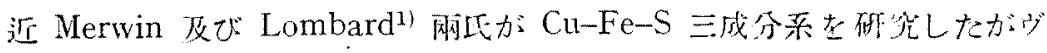

1) Schwartz, G. M. : Intergrowths of chalcopyrite and cubanite. Econ. Geol. 22. 1927, pp. $44 \sim 61$.

2) Borchert, H.: Cber Entmischungen im System Cu-Fe-S und ihre Bedeutungen als "Geologische Thermometer". Chemie der Erde, Prd. 9, 1934. pp. 141 172.

3) Merwin, H. E. and Lombard, R. H. : The System, Cu-Fe-S. Econ, geol. 32, 1937. $203 \sim 284$. 


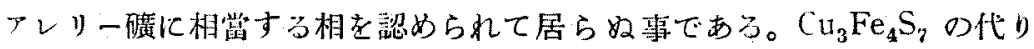

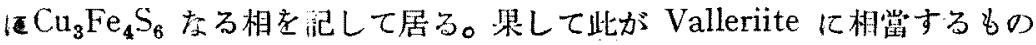

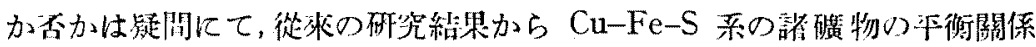
を詳しく淪ずるには佩データの不足を感ずる。

何狄にしても Vallerite に就いて經驗的に知られた事賽は，同䃥物方：

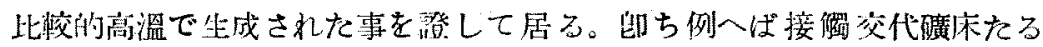
Kaveltorp, Sweden, 乘成乃至深熱水性交代磺床たる Boliden, Sweden

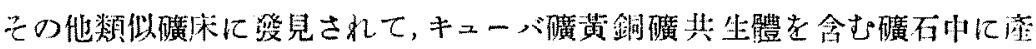
する。

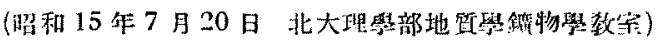

\section{會報及雜蛝}

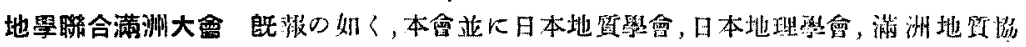

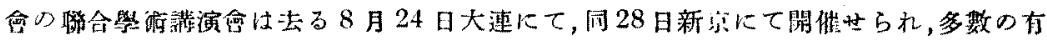

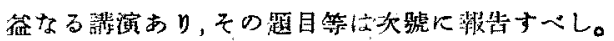

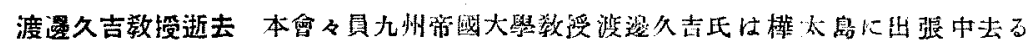
8月13日苪を以て逝去せらる。这に謹んで深厚なる用意を表す。 